\title{
TEMAS DE LITERATURA E CULTURA: OS DESAFIOS DA EDUCAÇÃO LITERÁRIA NO SISTEMA DE ENSINO TIMORENSE
}

\section{LITERATURE AND CULTURE THEMES: THE CHALLENGES OF LITERARY EDUCATION IN THE EAST TIMORESE EDUCATION SYSTEM}

\author{
Ana Margarida Ramos"
}

Resumo: Este texto apresenta sucintamente o programa da nova disciplina de Temas de Literatura e Cultura que, desde janeiro de 2012, passou a integrar a Componente de Ciências Sociais e Humanidades do Ensino Secundário Geral de Timor-Leste, em resultado do projeto de reestruturação curricular levado a cabo por uma equipa coordenada pela Doutora Isabel P. Martins, da Universidade de Aveiro (Portugal), dando conta dos princípios que nortearam a sua criação e esclareceram as escolhas curriculares realizadas. Analisa o seu processo de implementação no terreno, as principais dificuldades encontradas e antecipa alguns dos desafios futuros com vista ao desenvolvimento da educação literária num país sem tradição do seu ensino.

Palavras-chave: Timor-Leste, ensino, reestruturação, literatura, identidade

Abstract: This paper presents the syllabus of a new course, Literature and Culture Themes, that, since January 2012, joined the Curricular Component of Social Sciences and Humanities of East Timorese General Secondary Education, as a result of curricular restructuring project carried out by a team coordinated by Professor Isabel P. Martins, from the University of Aveiro (Portugal). It presents the principles that guided the creation of the syllabus and explains the curricular choices made during this process. The text also analyses the implementation development on the ground, the main difficulties founded and it anticipates some of the future challenges for the development of literary education in a country with no tradition of teaching literature at the secondary level of education.

Keywords: East-Timor, teaching, restructuring, literature, identity

\footnotetext{
* Professora do Departamento de Línguas e Culturas da Universidade de Aveiro (Portugal).
} 


\section{Introdução. Reestruturação curricular no Ensino Secundário Geral}

Concebida numa lógica de reforço da questão identitária, desenvolvendo-se em torno de temas culturais relevantes e fortemente ancorada no estudo do texto literário, central ao longo do programa trienal, a disciplina de Temas de Literatura e Cultura assumiu-se, desde o início, como uma das mais inovadoras e que mais desafios coloca a formadores, professores e alunos, bem como a responsáveis pela organização e gestão escolar em Timor-Leste

Trata-se de uma disciplina que surge integrada na componente de Ciências Sociais e Humanidades, do novo Plano Curricular para o Ensino Secundário Geral em Timor-Leste, no âmbito de um projeto de cooperação apoiado pelo IPAD Instituto Português de Apoio ao Desenvolvimento, pela Fundação Calouste Gulbenkian e pelo Fundo da Língua Portuguesa, desenvolvido por uma vasta equipa coordenada pela Doutora Isabel P. Martins, da Universidade de Aveiro. Este projeto, que foi realizado em estreita colaboração com o Ministério da Educação de Timor-Leste, desenvolveu-se entre 2009 e 2013, tendo sido complementado por um Programa de Formação Contínua de Formadores e professores que se desenrolou entre 2012 e 2014 (PFICP - Projeto de Formação Inicial e Contínua de Professores) e que aguarda, a breve trecho, desenvolvimentos com vista à sua continuidade.

O projeto inicial contemplou a elaboração de um Plano Curricular para o Ensino Secundário Geral e Programas, Manuais e Guias do Professor para as 14 disciplinas (e para os 3 anos de escolaridade) que integram esta nova proposta curricular e que ficaram a cargo da equipa da Universidade de Aveiro (Martins, 2013; Martins \& Ferreira, 2013; Martins \& Ferreira, 2015).

Todo o material pedagógico produzido, bem como outros produtos científicos e pedagógicos que dele resultaram estão acessíveis numa página na internet criada para o efeito em https://www.ua.pt/esgtimor/.

Refira-se que, no seguimento deste projeto, uma equipa de investigadores do Centro de Investigação Didática e Tecnologia na Formação de Professores (CIDTFF), da Universidade de Aveiro, desenvolveu, entre maio de 2013 e outubro de 2015, um projeto de investigação intitulado Projeto TIMOR - Avaliação do impacte da reestruturação curricular do ensino secundário em Timor-Leste - um estudo no âmbito da cooperação internacional, financiado pela Fundação para a Ciência e Tecnologia, pelo Programa Operacional Factores de Competi- 
tividade e pelo Fundo Europeu de Desenvolvimento Regional, cujos principais objetivos passavam, como a sua designação indicia, pela avaliação do impacte do projeto inicial, tendo realizado, no terreno, um acompanhamento da sua implementação, cujos resultados, compilados em dois volumes monográficos (Cabrita, 2015a e 2015b), nos serão particularmente úteis neste estudo.

\section{Temas de Literatura e Cultura. Programa e materiais pedagógicos}

Relativamente ao programa da disciplina aqui em análise, refira-se que o mesmo foi arquitetado em torno da progressiva valorização da literatura e cultura timorenses e promovendo a sua gradual legitimação e canonização através do estudo dos seus autores e respetivas obras literárias. Este é, possivelmente, um dos aspetos mais inovadores da disciplina em questão, sem tradição no contexto timorense, mas também mais exigentes, como veremos, do ponto de vista da sua implementação, dada não só a impreparação dos docentes, mas até a falta de sensibilização dos decisores políticos para uma área completamente desconhecida, aspeto a que voltaremos neste texto.

O programa assenta ainda na potenciação da relação com a lusofonia, promovendo o conhecimento das literaturas e culturas dos vários países de língua oficial portuguesa (Portugal, Brasil, Angola, Moçambique, Guiné Bissau, São Tomé e Príncipe e Cabo Verde). Tem especial incidência no universo contemporâneo e procurou mapear - com a ajuda dos colaboradores timorenses - temas e universos de referência relevantes, próximos e identificáveis, dos alunos e dos professores, em estreita relação com a História recente do país e com questões candentes da atualidade. O programa revela igualmente preocupação com a valorização de modos e géneros literários diferentes, como a poesia, o conto (tradicional e de autor), o romance, mas também as memórias e a biografia, por exemplo, dando preferência aos textos integrais e às versões originais (mesmo se mais difíceis).

Aspeto transversal a todo o programa, e presente de modo mais ou menos explícito, é a questão da educação literária, ou seja, a formação de leitores capazes de interagir de forma eficaz e produtiva com o texto literário, ativando eficientemente as múltiplas possibilidades de leitura que o enformam. Trata-se de uma competência relevantíssima do ponto de vista pessoal e académico, atendendo 
a que a leitura do texto literário, enquanto atividade de índole pessoal e subjetiva, é condicionada pela experiência e pela enciclopédia do leitor, incluindo o seu intertexto leitor (Mendoza Fillola, 2001). Nessa leitura, realizada tanto ao nível do significado explícito como implícito, isto é, das mensagens ocultas, das ironias e das alusões intertextuais, por exemplo, tem especial impacto o conhecimento da língua, do mundo, da cultura e da literatura, alargando e enriquecendo as referências pessoais, ao mesmo tempo que se procura promover as capacidades de questionamento, de reflexão, de espírito crítico, numa lógica de desenvolvimento gradual da personalidade. No caso timorense, estas questões apresentam-se com uma pertinência e relevância acrescidas em resultado do caráter emergente (Esperança, 2005; Ramos, 2012a e 2012b) da sua literatura, a que se somam circunstâncias contextuais, do ponto de vista cultural, político, histórico, social e educativo, associadas ao insignificante relevo social da literatura e da leitura em Timor-Leste.

Refira-se que os manuais do aluno da disciplina de Português, da componente geral e, nessa medida, obrigatória para todos os alunos, também incluem textos literários timorenses em diferentes anos, com especial incidência no 10 ำ ano, onde surge um excerto (adaptado) do conto "Cáspita", de Luís Cardoso, o poema "Florindo eternamente", de Abé Barreto Soares, o poema "Poema ancestral", de Crisódio T. Araújo, além de excertos (adaptados) dos romances Olhos de coruja olhos de gato bravo, e A última morte do coronel Santiago, ambos de Luís Cardoso. No 11ㅇan ano, uma unidade tem como epígrafe o poema "Rota", de Fernando Sylvan. No $12 \circ$ ano, a literatura timorense está ausente. Nos materiais desta disciplina, observa-se uma dimensão mais "instrumental" do texto literário (ao serviço de outras competências, nomeadamente linguísticas e comunicativas, centrais no seu programa); o caráter pontual do texto literário de autoria timorense (presente ao nível da narrativa e da lírica), ainda que se verifique uma seleção criteriosa dos textos e dos autores (tendencialmente próximos do "cânone"). Também é constatável a preferência por excertos e versões adaptadas dos textos, em detrimento da leitura integral e das versões originais, para além da presença de outros textos literários de autores de língua portuguesa oriundos de outros espaços, nomeadamente o africano. É ainda relevante a opção pela presença de textos literários de temática timorense, como ilustram as escolhas de Ruy Cinatti ou do romance de António Veladas cuja ação se situa em 
Timor-Leste, nos momentos que antecedem e seguem o referendo de 1999, por exemplo.

Neste medida, à falta da conformação de um cânone da literatura nacional que colabore na sua progressiva legitimação, soma-se a juventude do país, cuja independência (2002), com pouco mais 13 anos, já foi atravessada por uma grave crise social e política (2006) - depois da invasão e ocupação indonésia (1975-1999), a que se seguiu o apoio da ONU (1999-2002); um sistema educativo ainda em processo de reconstrução (Ramos e Teles, 2012), depois de ter sido totalmente destruído em 1999 (e parcialmente em 2006), com graves debilidades a vários níveis; o facto de a cultura timorense ser predominantemente oral, caracterizada pela presença, num território exíguo, de mais de três dezenas de línguas e dialetos, com implicações ao nível da manutenção de debate em torno da política linguística do país, o que se repercute - e alguns casos amplifica - no sistema de ensino e no desenvolvimento de uma produção literária autóctone. Assim, constata-se, do mesmo modo, a inexistência de uma produção literária de autoria timorense sedeada no país (ou que aí circule de forma significativa), seja em língua portuguesa, seja em tétum.

Face a esta realidade, observável em várias missões no terreno e no contacto direto com os professores e outros agentes educativos, tomaram-se uma série de decisões com vista à elaboração dos materiais didáticos, quer do ponto de vista da seleção dos conteúdos, quer das metodologias a introduzir de modo a que, sem pôr em causa os objetivos principais, articulados com as melhores práticas internacionais na área, cientificamente validadas, pudéssemos colmatar algumas das lacunas existentes, incluindo ao nível da formação de professores, e contribuir, dentro do contexto existente, para a conformação de um cânone de obras de literatura timorense, suscetível de responder aos desafios educativos, mas evidenciando os fatores de seletividade, continuidade e formatividade (Reis, 1995) que o sustentam.

Procedeu-se, assim, à identificação de temas e áreas de formação prioritárias, numa lógica de progressão em termos de complexidade e exigência das aprendizagens ao longo dos três anos do ciclo de formação, de variedade e de diversidade das propostas apresentadas, permitindo, também, opções aos professores em termos de seleção de textos e atividades (entre várias alternativas disponibilizadas). Com vista a colmatar as lacunas diagnosticadas ao nível dos conhecimentos científicos e didáticos dos professores, construiu-se o Guia do 
Professor como um instrumento de autoformação do docente na área científica e na área pedagógico-didática (além de uma ferramenta de apoio ao trabalho em sala de aula, com a introdução de glossários, cenários de resposta para todas as questões do Manual do Aluno, textos teóricos, materiais de avaliação e de registo, atividades complementares, etc.)

Em termos da estruturação do ciclo, observa-se uma gradual extensão dos textos literários trabalhados, sempre que possível disponibilizados integralmente, nas versões originais e a variedade de géneros literários selecionados, complementados com outros textos, nomeadamente não-literários, e com outras modalidades artísticas, como a música, a pintura, o artesanato, a fotografia ou o cinema. A relação entre a leitura e a escrita é igualmente alvo de atenção e de trabalho em todas as unidades dos três manuais do aluno.

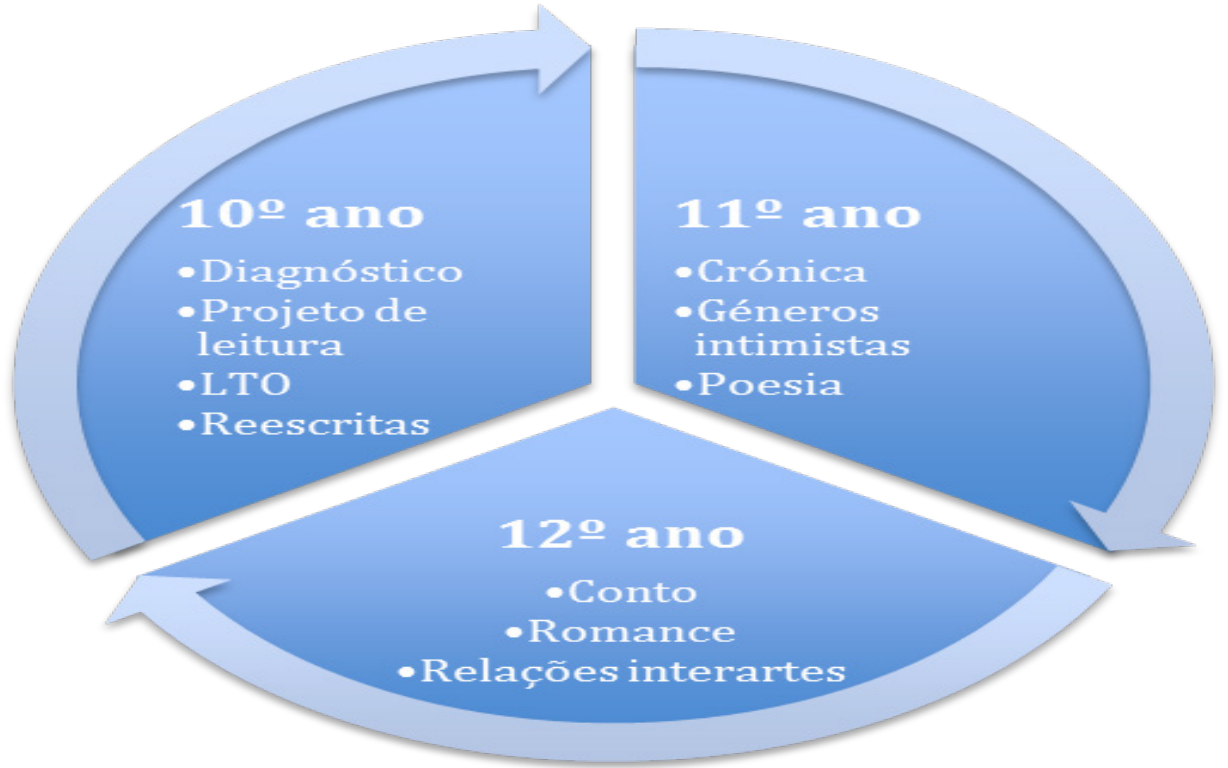

No que à literatura timorense diz respeito, no 10 ำ ano são apresentadas, por exemplo, versões recolhidas oralmente de textos da tradição oral timorense (Eduardo dos Santos, Ezequiel Enes Pascoal, Artur Basílio de Sá, e outros), mas também versões literárias da Lenda de Timor por Fernando Sylvan e Luís Cardoso, "O crocodilo que se fez Timor" e "O crocodilo fez-se ilha", respetivamente, permitindo a comparação e a reflexão sobre questões ligadas às reescritas, por exemplo, mas também à intertextualidade, que surge reforçada através da 
presença do poema "Avó Crocodilo", de Xanana Gusmão, que alude à mesma lenda. No caso concreto do estudo da literatura tradicional de transmissão oral, é valorizado o contexto timorense e é sublinhada a importância e o relevo das formas literárias, mapeando a sua evolução e presença em textos contemporâneos. $O$ reconhecimento dos referentes poderá aproximar professores e alunos dos conteúdos, promovendo o interesse através da sua identificação e posterior valorização. A introdução ${ }^{1}$ desta disciplina neste ano letivo contempla unidades de cariz diagnóstico e propedêutico, preparando os alunos para os desafios de aprendizagem posteriores.

No caso do 11 ano, foram incluídos no Manual do Aluno vários textos de autoria timorense, em diferentes unidades. É o caso de duas crónicas literárias de Luís Cardoso, que apresentam como textos de índole memorística, e, sobretudo, de um conjunto muito alargado de textos poéticos numa das unidades centrais deste ano letivo. Aí surgem quatro poemas da coletânea Mar Meu, de Xanana Gusmão ("Marta, queridinha”, "Esperanças rasgadas", "Oh! Liberdade!", "Gerações"), uma poema de Borja da Costa ("Os ventos no teu dorso"), três poemas de Jorge Lauten ("Enterrem meu coração no monte Ramelau", "Não mais sob a árvore de bô", "Pequena ode para Nicolau Lobato"), dois poemas de Jorge Barros Duarte "O 'Caleic'", "Menino de Timor"), dois poemas de Afonso Busa Metan ("Emancipação", "Ainda"), um poema de Danilio de Barros ("E eu pergunto, o que se passa na minha terra?"), quatro poemas de João Aparício ("Poema da Paz", "Minha Paz", Aldeia das Crianças", "Estrela dos Guerrilheiros"), dez poemas de Fernando Sylvan ("Infância", "Meninos e Meninas", "Menino Grande", "Mensagem do Terceiro Mundo", "In Memoriam", Poema Horrível", "História para as crianças portuguesas", "Invasão", "Jornal", "Luta”), além de mais quatro poemas muito breves do livro Mulher ou o livro do teu nome, e um poema de Gabriela Carrascalão ("Menino abandonado"). Associados a distintos temas (Resistência; Infância; Amor; Natureza), estes textos configuram uma seleção que integram autores de diferentes gerações, reconhecimento e, até, qualidade literária. Exprimem, contudo, a vitalidade da escrita poética de autoria timorense, particularmente relevante durante o período da resistência, contribuindo, pelo

\footnotetext{
${ }^{1}$ O Guia do Professor do 10 ㅇao integra muitos materiais que pretendem auxiliar os docentes em várias tarefas, incluindo vários exemplos de fichas de leitura, fichas de registo, grelhas de avaliação, além de um glossário cuja consulta poderá ser útil em anos posteriores.
} 
destaque que lhes é conferido, mas também pelas propostas de leitura que deles apresentam, para a identificação de um "corpus" de vozes incontornáveis da poesia timorense ${ }^{2}$, associado às figuras de Fernando Sylvan, Jorge Lauten e João Aparício. Em vários momentos, são sugeridos diálogos com outras vozes, de outras latitudes, com vista à comparação, mas também ao alargamento de referências literárias e culturais. O Manual do Aluno encerra com uma unidade dedicada ao estudo da obra de Ruy Cinatti de temática timorense. Não se tratando de um autor timorense, convém sublinhar que Timor-Leste foi recriado e revisitado em vários dos seus textos, nem todos de índole literária. A relação profunda que estabeleceu com o país e com alguns dos seus habitantes levam a que seja, ainda hoje, considerado como uma espécie de filho adotivo de Timor, sendo usual que aí surja visto mais como timorense do que como português, aspetos que, naturalmente, foram tidos em consideração na construção dos materiais.

O $12^{\circ}$ ano, dedicado às formas narrativas, inclui, entre outras propostas, os seguintes textos de autoria timorense: conto "Viemos Adorá-LO", de Hercus Santos, que dialoga intertextualmente com o conto de Sophia de Mello Breyner Andresen, $O$ Anjo de Timor, igualmente alvo de leitura integral; o romance Crónica de uma Travessia, de Luís Cardoso, alvo de leitura integral, mas também possível de estudar através da análise intensiva de excertos, dada a previsível dificuldade em obter a obra em Timor-Leste; três poemas de Maria Gabriela Carrascalão ("Loi Sa'e", "Alma Timor", "Timor das Acácias Feridas"), alvo de leitura em articulação com algumas pinturas da mesma autora; um poema de Xanana Gusmão ("Oh! Liberdade!), igualmente alvo de uma leitura comparada com a produção ao nível das artes visuais do autor; o poema "Timor", de Hercus Santos. Saliente-se, relativamente a este ano letivo, o relevo da opção pela leitura integral de um romance de autoria timorense, alvo de múltiplas traduções e prémios, cuja temática, bem como localização geográfica e temporal, permitem a identificação e o reconhecimento por parte dos alunos, podendo revelar-se uma leitura de considerável impacto pessoal. Luís Cardoso é, sem dúvidas, o autor timorense contemporâneo mais relevante, ainda que viva há várias décadas em Portugal, onde estudou e teve grande relevância no movimento de resistência externo. Alvo de vários estudos, nomeadamente teses de Mestrado e Doutoramento, realizadas principalmente em Portugal e no Brasil, o autor tem uma publicação

\footnotetext{
${ }^{2}$ Sobre a poesia timorense e as suas figuras mais relevantes, ver Dumas, 2000.
} 
assídua, sobretudo no domínio do romance, com incursões pontuais na crónica e no conto, tendo, nos últimos anos, confirmado a sua maturidade literária, assumindo de forma definitiva Timor como o grande tema - talvez mesmo a grande personagem - da sua obra.

A sua produção literária, revelando afinidades com o romance pós-moderno, em particular a metaficção historiográfica, pela fragmentação narrativa e discursiva, pelo questionamento e reflexão sobre a História, problematizando os discursos oficiais e propondo outras leituras para os acontecimentos, pelo seu caráter ucrónico no tratamento do tempo, não se esgota nessa leitura, até porque muitas dessas características não resultam da "adesão" do autor a correntes literárias ou a tendências estéticas, mas do próprio contexto e pensamento timorenses, onde os tempos, por ação dos ritos, se atualizam e misturam, onde a palavra é ação, convocando memórias, indivíduos, seres e acontecimentos extraordinários. Ler cada um dos romances de Luís Cardoso é, por isso, uma oportunidade única de ter acesso privilegiado a uma cultura e a um universo singulares, uma espécie de viagem ou vertigem no espaço e no tempo ao imaginário timorense construído entre a realidade e a magia, resgatando do esquecimento, por via da literatura escrita, uma memória e um povo, mas também construindo, através dessa mesma literatura e do romance, o seu futuro e a sua identidade. No caso do romance escolhido para o programa da disciplina de Temas de Literatura e Cultura, Crónica de uma travessia. A época do Ai-Dik-Funam (1997), trata-se de uma obra de estreia onde assistimos ao cruzamento de uma linha narrativa de índole referencial, com referências concretas a factos e a figuras conhecidas, com outra de carizautobiográfico em registo memorialista. É desta interseção que se constrói - ou se procura construir - uma imagem unificadora de Timor-Leste, dando conta da instabilidade e da transitoriedade que marca o território e, consequentemente, as suas gentes, vivendo uma insularidade particular. A memória e a identidade são, deste modo, os eixos coesivos de um romance onde as viagens, realizadas em múltiplas direções e com distintas finalidades, têm lugar de destaque, estruturando a realidade e a própria organização temporal e espacial. É por isso que ao reescrever a sua história e a da sua família, em particular a do próprio pai, o narrador reflete sobre a história de Timor-Leste e sobre a forma como ela se confunde com a dos seus habitantes. Estes elementos temáticos e formais, a que se associa um registo fluído e acessível, estiveram nas razões da escolha da obra, possivelmente a mais adequada para um público 
juvenil, até porque o romance recupera muitas memórias de infância e de juventude do próprio autor.

Para além dos textos de autoria timorense, sublinhe-se a presença, em diferentes anos, de literatura de temática timorense, nomeadamente de Sophia de Mello Breyner, Ruy Cinatti, Teresa Rita Lopes, Nuno Higino, António José Borges, José Eduardo Agualusa, Mia Couto, dando a conhecer aos alunos a repercussão da cultura deste país em outras literaturas e contextos. O programa distingue-se também pela valorização de géneros diferentes, como a poesia, o conto (tradicional e de autor), o romance, as memórias e a biografia, por exemplo, promovendo o contacto dos alunos com várias poéticas de distintos autores/ criadores. É igualmente visível a valorização de textos literários de temáticas de cariz identitário, com forte associação à história recente de Timor-Leste, em particular os anos da ocupação indonésia e de resistência, estabelecendo relações entre a literatura e o contexto em que se desenvolve, por ser reconhecidamente um tema instigante, capaz de suscitar respostas pessoais dos alunos. Presente ao longo dos três anos letivos, a literatura timorense vai ganhando um relevo crescente, surgindo em praticamente todas as unidades dos manuais. Merece finalmente destaque a preferência dada aos textos integrais e a versões originais, mesmo se estas se apresentam mais difíceis ou mais exigentes em termos de leitura.

\section{Implementação. A educação literária em Timor-Leste}

A implementação de um programa com estas características e estas exigências num contexto com as limitações do timorense é particularmente difícil e desafiadora. Desde logo, pela falta de tradição de estudo e investigação na área da literatura, incluindo ao nível superior, com claras repercussões na formação de professores. A realidade timorense, ainda fortemente marcada por níveis muito elevados de analfabetismo e iliteracia, caracteriza-se por uma generalizada insuficiência de hábitos e de práticas de leitura, também decorrente da inexistência de produção editorial sedeada em território timorense, estando os livros e a literatura circunscritos a elites culturais e sociais. Deste modo, a transmissão cultural no território é ainda grandemente baseada no circuito oral, sobretudo quando associado às línguas locais, a grande maioria das quais ágrafa. Mesmo 
do ponto de vista da investigação na área, ela é quase integralmente realizada fora de Timor-Leste, não encontrando aí grande eco ou sendo mesmo completamente desconhecida. Exceções pontuais são as teses de Mestrado realizadas por alguns docentes do Departamento de Língua Portuguesa da UNTL em Portugal e no Brasil nos últimos anos.

Relativamente ao sistema de ensino e ao processo de reestruturação no qual se enquadra a disciplina de Temas de Literatura e Cultura, as dificuldades diagnosticadas ao longo do processo, inclusivamente apontadas de forma repetida em vários relatórios de missões de trabalho a Timor-Leste, passaram (e continuam a passar) pelos problemas de identificação e recrutamento de docentes com perfil adequado à disciplina e às exigências que ela coloca, nomeadamente tendo em conta a novidade que caracteriza a sua introdução num currículo onde o estudo da literatura não tem tradição (Cabrita, 2015b, p. 31). Além disso, entre os professores recrutados, nas áreas científicas mais variadas, incluindo as das ciências exatas, é notória e constatada, a falta de formação dos professores (e até de sensibilização para as especificidades da área) em termos científicos, mas também em termos didáticos, nomeadamente metodológicos (Cabrita, 2015b, p. 63), tendo em conta as novidades que o programa preconiza, propondo um ensino-aprendizagem centrado nos alunos, valorizando diferentes tipos de atividades e de modalidades de trabalho em sala de aula. Somam-se as grandes dificuldades em termos de domínio da língua portuguesa dos professores (com reflexo nos alunos, mas também na compreensão dos próprios textos e materiais disponibilizados), muitas vezes avaliados pelos intervenientes no processo educativo como difíceis, exigentes e pouco adequados (Cabrita, 2015a, p. 38-42). A própria formação de professores para a lecionação do novo currículo, apesar de ter existido, conheceu várias dificuldades, quer em termos de recrutamento de formadores timorenses e de formandos, quer de abrangência em termos territoriais e geográficos. Pontual, em alguns casos isolada ou muito circunscrita, tendo em conta os recursos e meios envolvidos, a formação revelou resultados interessantes, mas limitados em termos de abrangência e face às necessidades existentes, carecendo de ser aprofundada, continuada e alargada para atingir os objetivos e poder ter um impacto mais significativo.

Em termos logísticos e estruturais, mantêm-se, apesar de algumas intervenções realizadas nos últimos anos, a falta de infraestruturas adequadas nas escolas, não só em quantidade, como em qualidade, com a inexistência de bibliote- 
cas e de salas de leitura e de acervos de livros de apoio em número significativo, sobretudo nas escolas da rede pública ${ }^{3}$. Em relação aos materiais pedagógicos elaborados, verifica-se também a sua insuficiência e/ou a sua irregular distribuição pelo território. Mesmo quando os manuais chegam às escolas são com frequência insuficientes para os alunos existentes. Na maior parte dos casos, não são distribuídos pelos os alunos, mantendo-se inacessíveis ou só pontualmente acessíveis, através de empréstimo ou consulta na biblioteca da escola. É certo que a montante destas evidências há outras fragilidades no sistema educativo, mesmo do ponto de vista de organização, de comunicação e de implementação das reformas e que, de forma mais ou menos indireta, intervêm no processo, condicionando o seu sucesso e/ou a sua melhoria gradual com vista a uma efetiva consolidação.

\section{Considerações finais. Dificuldades e desafios}

Desde os momentos iniciais do desenho do projeto de Reestruturação do Ensino Secundário Geral timorense estivemos conscientes dos enormes desafios que se colocavam à disciplina de Temas de Literatura e Cultura. A sua inclusão no Plano Curricular foi questionada e debatida com as autoridades timorenses, com os grupos de trabalho formados em Timor-Leste e com um vasto leque de interlocutores, em escolas, na UNTL, em ONG's, no Parlamento Nacional, onde se incluem várias figuras de relevo da sociedade timorense. A uma reação inicial de estranhamento, motivada pelo desconhecimento em relação ao conteúdo, seguia-se quase sempre uma curiosidade pelo tema e pelas suas potencialidades, sobretudo tendo em consideração a sua relação com o contexto timorense, o fortalecimento da valorização da cultura nacional, com repercussões de cariz identitário.

Destaque-se, desde logo, como aspeto estruturante no desenho do programa da disciplina de Temas de Literatura e Cultura, o relevo e a importância que a leitura literária tem na formação de leitores, mas também de cidadãos pensantes,

\footnotetext{
${ }^{3}$ Algumas escolas da rede privada, sobretudo as associadas ao ensino promovido pelas escolas católicas, apresentam características diferentes, quer ao nível das infraestruturas, quer dos recursos materiais e humanos disponíveis.
} 
ativos e interventivos. Complexa e abrangente, a competência literária resulta de um conjunto muito amplo de conhecimentos e dimensões que, perante os estímulos textuais, se ativam e atuam na compreensão, apropriação e fruição do objeto artístico que é o texto literário. Entre eles encontram-se as competências linguísticas de vária ordem, conhecimentos sobre o literário, as suas regras, estruturas, sistema e convenções, conhecimentos intertextuais, semióticos, culturais e estratégicos. A sua mobilização simultânea resulta numa das tarefas cognitivamente mais complexa de que há conhecimento, mas também emotiva e humanamente enriquecedora. Perante esta proposta, são evidentes os enormes desafios que se colocam ao sistema de ensino timorense, ainda em fase de desenvolvimento e consolidação, enfrentando inúmeras dificuldades e constrangimentos de toda a ordem. As exigências mais evidentes têm a ver com o perfil do professor de Temas de Literatura e Cultura, idealmente um leitor competente, de modo a poder ser um exemplo/modelo para os alunos, possuindo uma sólida formação literária, em termos teóricos e práticos (Cerrillo, 2010), além de competências pedagógicas e didáticas várias, recorrendo à leitura como fonte de prazer, de informação, de aprendizagem, e como forma de aperfeiçoamento e enriquecimento linguístico e pessoal, adequando a seleção dos livros e dos textos às competências de leitura dos alunos (Colomer, 2010). Trata-se, como sabemos e os estudos realizados recentemente têm vindo a sublinhar, de um perfil muito distante da realidade existente, que apresenta, a este nível, limitações significativas (só comparáveis com as disciplinas de Geologia e Tecnologias Multimédia), dado que o recrutamento de docentes se tem revelado completamente incoerente e desadequado. Conhecendo a realidade e os constrangimentos existentes, foram realizadas algumas opções metodológicas com vista a mitigar algumas dificuldades, entre as quais se encontram a seleção muito criteriosa dos textos a trabalhar, incluídos sempre que possível em versão integral, dada a carência de recursos, uma vez que o ensino da literatura exige um trabalho com textos com sentido, com coerência e organização interna. Conscientes do longo caminho a percorrer, sobretudo em termos de formação de professores, tanto ao nível inicial como continuado, defendemos cada vez mais a importância do ensino da literatura no contexto timorense, relevante em termos da consolidação de uma literatura emergente, com consequências ao nível da afirmação identitária, tanto do ponto de vista linguístico, como cultural e, até, social e político. 
Outros fatores relevantes do ponto de vista da consolidação do sistema literário timorense, para além da sua presença na escola e nos documentos programáticos, passam pela investigação académica e científica, nomeadamente através da realização de teses e da publicação de artigos em revistas de referência. Outros aspetos a ter em conta são a tradução das obras literárias e os prémios. Sobre a questão da emergência do sistema literário timorense, atentar, por exemplo, na presença de prefácios legitimadores, da autoria de figuras de referências das literaturas em língua portuguesa, nas obras de estreia de autores timorenses, como aconteceu com José Eduardo Agualusa (1997) no romance de estreia de Luís Cardoso, com Mia Couto (1998), na coletânea de poesia de Xanana Gusmão, ou com Sophia de Mello Breyner Andresen (1999), num volume de poesia de João Aparício, curiosamente em anos sucessivos.

A proposta de programa que apresentamos, suscetível, obviamente, de críticas, reformulações e ajustes, sustenta-se no entendimento da leitura literária como um direito e uma urgência, aspetos que, no contexto específico de Timor-Leste, adquirem um relevo ainda mais significativo e mais premente.

\section{Referências:}

\section{Documentos programáticos e materiais didáticos:}

Jornal da República (Timor-Leste), DECRETO-LEI N.o 47/2011 de 19 de Outubro, Série I, N. 38 (pp. 5308-5314) - Aprova o plano curricular do Ensino Secundário Geral e o respectivo regime de implementação

RAMOS, Ana Margarida, ALMEIDA, Ana Paula, PEREIRA, Paulo Alexandre e SILVA, Sara Reis da. Programas do 10, 11ㅇ e 12ㅇao de Temas de Literatura e Cultura. Díli: Ministério da Educação de Timor-Leste, 2011.

RAMOS, Ana Margarida, ALMEIDA, Ana Paula, PEREIRA, Paulo Alexandre e SILVA, Sara Reis da. Manual do aluno de Temas de Literatura e Cultura - 10ano. Díli: Ministério da Educação de Timor-Leste, 2011 (ISBN 978-989-8547-17-0).

RAMOS, Ana Margarida, ALMEIDA, Ana Paula, PEREIRA, Paulo Alexandre e SILVA, Sara Reis da. Guia do Professor de Temas de Literatura e Cultura - 10ano. Díli: Ministério da Educação de Timor-Leste, 2011 (ISBN 978-989-8547-04-0). 
RAMOS, Ana Margarida, ALMEIDA, Ana Paula, PEREIRA, Paulo Alexandre e SILVA, Sara Reis da. Manual do aluno de Temas de Literatura e Cultura - 11a ano. Díli: Ministério da Educação de Timor-Leste, 2012 (ISBN 978-989-8547-44-6).

RAMOS, Ana Margarida, ALMEIDA, Ana Paula, PEREIRA, Paulo Alexandre e SILVA, Sara Reis da. Guia do Professor de Temas de Literatura e Cultura - 11ano. Díli: Ministério da Educação de Timor-Leste, 2012. (ISBN 978-989-8547-58-3)

RAMOS, Ana Margarida, ALMEIDA, Ana Paula, PEREIRA, Paulo Alexandre e SILVA, Sara Reis da. Manual do aluno de Temas de Literatura e Cultura - 12ano. Díli: Ministério da Educação de Timor-Leste, 2013 (ISBN: 978-989-753-121-7).

RAMOS, Ana Margarida, ALMEIDA, Ana Paula, PEREIRA, Paulo Alexandre e SILVA, Sara Reis da. Guia do Professor de Temas de Literatura e Cultura - 12 ano. Díli: Ministério da Educação de Timor-Leste, 2013 (ISBN: 978-989-753-135-4).

\section{Outras referências:}

AGUALUSA, José Eduardo. Como se fosse um prefácio. In CARDOSO, L. Crónica de uma travessia. A época do Ai-Dik-Funam. Lisboa: Publicações Dom Quixote, 1997, p. 5-6.

ANDRESEN, Sophia de Mello Breyner. Prefácio. In APARÍCIO, J. À Janela de Timor. Lisboa: Caminho, 1999, p. 11-17.

CABRITA, Isabel. (coord.). Implementar a Reestruturação Curricular do Ensino Secundário Geral em Timor-Leste: Construindo Qualidade. Aveiro: UA Editora, 2015a.

CABRITA, Isabel (coord.). Ensino Secundário Geral em Timor-Leste: Perspetivando o futuro. Aveiro: UA Editora, 2015b.

CERRILLO TORREMOCHA, Pedro. Sociedad y Lectura. La Importancia de los Mediadores en Lectura. In Formar Leitores para Ler o Mundo. Lisboa: Fundação Calouste Gulbenkian, 2010, p. 95-104.

COLOMER, Teresa. Planificar la lectura en la Escuela. In Formar Leitores para Ler o Mundo. Lisboa: Fundação Calouste Gulbenkian, 2010, p. 83-93.

COUTO, Mia. Prefácio. O Verso e o Universo / Preface. Verse and Universe. In GUSMÃO, X. Mar Meu. Poemas e Pinturas/My Sea of Timor. Poems and Paintings. Porto: Granito/Instituto Camões, 1998, p. 6-9.

DUMAS, Catherine. Bref aperçu de la poésie timoraise. Latitudes, no 8, p. 21-24, 2000.

ESPERANÇA, João Paulo. Um brevíssimo olhar sobre a Literatura de Timor. Mealibra Revista de Cultura, no 3.16, p. 131-134, 2005.

MARTINS, Isabel P. (2013). Science Education in general secondary school in East-Timor: from research to cooperation. Journal of Science Education, no 14, pp. 20-23, 2013. 
MARTINS, Isabel P., \& FERREIRA, Ângelo. (2013). A Reestruturação Curricular do Ensino Secundário Geral de Timor-Leste. Um caso de cooperação da Universidade de Aveiro no domínio da educação. In MORAIS, C., \& COIMBRA, R. L. (org.). Pelos Mares da Língua Portuguesa I. Aveiro: Universidade de Aveiro, 2013, p. 97-110.

MARTINS, Isabel P., \& FERREIRA, Ângelo. Ensinar e Aprender em Português em Timor-Leste: O caso do Ensino Secundário Geral. In FERREIRA, A. M. \& BRASETE, M. F. (org.). Pelos Mares da Língua Portuguesa 2. Aveiro: Universidade de Aveiro, 2015, p. 395-408

MENDOZA FILLOLA, Antonio. El Intertexto Lector. Cuenca: Ediciones de la Universidad de Castilla-La Mancha, 2001.

RAMOS, Ana Margarida. Da resistência política à libertação amorosa: eixos temáticos da poesia de Fernando Sylvan. Ellipsis - Journal of the American Portuguese Studies Association, no 10, p. 141-159, 2012a.

RAMOS, Ana Margarida. Literatura timorense: da emergência à legitimação, Caderno Seminal Digital, Rio de Janeiro, no 18, pp. 149-160, 2012 b.

RAMOS, Ana Margarida e TELES, Filipe. Memória das políticas educativas em Timor-Leste. A consolidação de um sistema (2007-2012). Aveiro: Universidade de Aveiro, 2012. REIS, Carlos. O Conhecimento da Literatura. Introdução aos Estudos Literários. Coimbra: Almedina, 1997. 